\title{
Real Impact of Varicocele Surgery on Male Fertility
}

\author{
Bouzid Balla $^{1 *}$, N Belcaid ${ }^{1}$, A Elkaoukabi ${ }^{2}$, A Chatar ${ }^{1}$, A Akjay ${ }^{1}$, A Ameziane ${ }^{1}$, A Lakrabti ${ }^{1}$, K Lmezguidi ${ }^{1}$ and $^{\text {A }}$ \\ A Ammani ${ }^{1}$
}

${ }^{1}$ Departement of urology, Military Hospital Moulay Ismail, Morocco

${ }^{2}$ Departement of Department of General and Visceral, Military Hospital Moulay Ismail, Morocco

*Corresponding author: Bouzid Balla, Department of urology, Military Hospital

Moulay Ismail, Meknes, Morocco.

Received Date: July 23, 2019

Published Date: August 01, 2019

\begin{abstract}
Varicocele is among the most common causes of male infertility. It is also one of the most controversial issues in the field of Andrology, especially regarding why, when and to whom varicocelectomy should be applied. Many experts believe that the surgical repair of varicocele should be applied only in a meticulously selected group of infertile men, although there are no generally accepted criteria. Up to now, the only confirmed prognostic factor for achievement of pregnancy after varicocelectomy is the age of the female partner. We perform a retrospective study that collected 120 patients over 7 years between 2010-2017 in urological department at the Military Hospital Moulay Ismail in Meknes, Morocco, to evaluate the issues currently associated with varicocele treatment in infertile men.
\end{abstract}

Keywords: Male infertility; Pregnancy rate; Varicocele; Surgical repair of varicocele

\section{Introduction}

Varicocele is a common male pathology that affects about $11.7 \%$ of the adult male [1] whose incidence is even more important in the population of infertile men $40 \%$ of men with primary infertility and $80 \%$ of men with secondary infertility, The presence of a varicocele does not always affect spermatogenesis, as it has been reported that only $20 \%$ of men with documented varicoceles suffer fertility problems; the real interest of the cure of the Varicocele on improving male fertility remains unclear [2]. However, it is recommended to perform clinical varicocele cure in the presence of oligospermia and infertility of 2 years in the absence of other etiologies [3]. The objective of our study is to evaluate the impact of the varicocele surgical cure on the improvement of the parameters of the spermogram and the reason of effective pregnancy.

\section{Materials and Methods}

Through a retrospective study that collected 120 patients over 7 years between 2010-2017. All patients are operated for clinical varicocele associated with a spermogram abnormality and carriers of infertility of male origin more likely.

Male infertility in our survey was defined by the association of:

1) Inability to procreate after one year of unprotected frequent sex. It is called primary if the couple has never had a child, secondary if the patient already has one or more children, but cannot conceive a new child.

2) An alleged fertile wife.

The clinical (age, stage of varicocele, primary or secondary infertility) and biological (sperm abnormality) characteristics of the patients were collected using an exploitation sheet.

Inclusion and exclusion criteria are summarized in (Tables $1 \& 2)$.

Table 1: Inclusion Criteria.

\begin{tabular}{|c|c|}
\hline 1 & Varicocele grade II or grade III according to Dublin Amelar \\
\hline 2 & Age between 25 and 60 years old \\
\hline 3 & Patient whose only cause of infertility remains varicocele \\
\hline 4 & $\begin{array}{r}\text { The proven infertility of the couple without gynecological } \\
\text { participation (presumably fertile wife) }\end{array}$ \\
\hline 5 & Varicocele coupled to 1 or more sperm abnormalities \\
\hline
\end{tabular}

Table 2: Exclusion Criteria.

\begin{tabular}{|c|c|}
\hline 1 & Patient with azoospermia (no spermatozoa detected) \\
\hline 2 & Patients with no spermogram preoperatively \\
\hline 3 & Varicocele infra clinical (grade I not operable) \\
\hline 4 & Patient whose infertility is associated with an endocrine \\
disorder.
\end{tabular}




\begin{tabular}{|c|c|}
\hline 5 & Spermogram normal preoperatively \\
\hline 6 & Gynecological origin of this infertility of the couple (wife) \\
\hline 7 & Single patient \\
\hline
\end{tabular}

In conjunction with this study, a telephone survey of all patients was conducted to identify patients who had a successful pregnancy after varicocele treatment. The different percentages and diagrams were calculated using Microsoft Office Excel 2010 software.

\section{Results}

120 patients with palpable varicocele with infertility participated in our study, after selecting patients for the survey, we classified the 70 non-included patients according to the reason for exclusion, and the results are summarized in (Table 3 ).

Table 3: The Different Categories of the Studied Population.

\begin{tabular}{|c|c|}
\hline Population & $120(100 \%)$ \\
\hline Included & $50(41.66 \%)$ \\
\hline Excluded & $70(58.33 \%)$ \\
\hline Azoospermia & 10 \\
\hline $\begin{array}{c}\text { No intra operative spermogram } \\
\text { available }\end{array}$ & 10 \\
\hline $\begin{array}{c}\text { Varicocele infra clinical } \\
\text { Endocrine disorders }\end{array}$ & 19 \\
\hline Normal spermogram & 10 \\
\hline Single & 20 \\
\hline
\end{tabular}

The mean age of patients was 38 years (25 and 60 years).
The reason for consultation in our series was mainly infertility $(83.3 \%)$

The left side was the most affected with $76 \%$ (Figure 1).

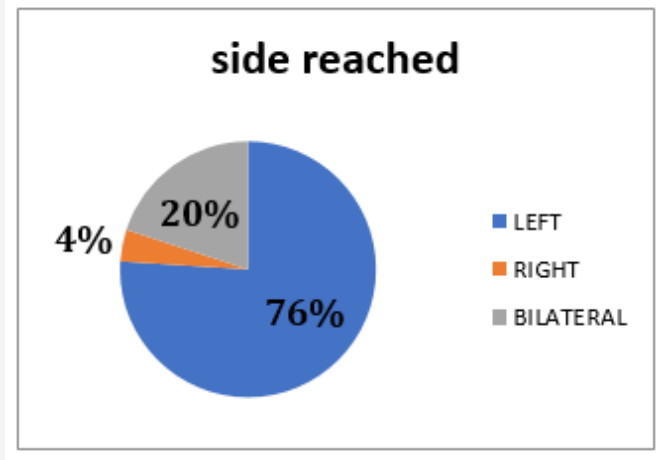

Figure 1: Side of the Varicocele in the Studied Population

The palpable varicocele was the inclusion criteria in our study. This varicocele was: grade 2: in 30 cases (60\%); grade 3: in 20cas (40\%). A scrotal + Doppler ultrasound and a renal ultrasound were performed in $70 \%$ of our patients. The most frequent abnormalities in order of frequency were respectively oligo-asthenoteratozoospermia in 29 cases (59\%) oligo-asthenospermia in 14 cases $(27 \%)$, asthenospermia in 7 cases (14\%). After the surgical treatment, we noted an improvement in 14 spermograms (28\%): 11 spermograms became normal, 2 spermogram with oligospermia and a single spermogram with mild asthenospermia, the number of spontaneous pregnancies obtained is practically $26 \%$ (13 couples) (Figure 2).

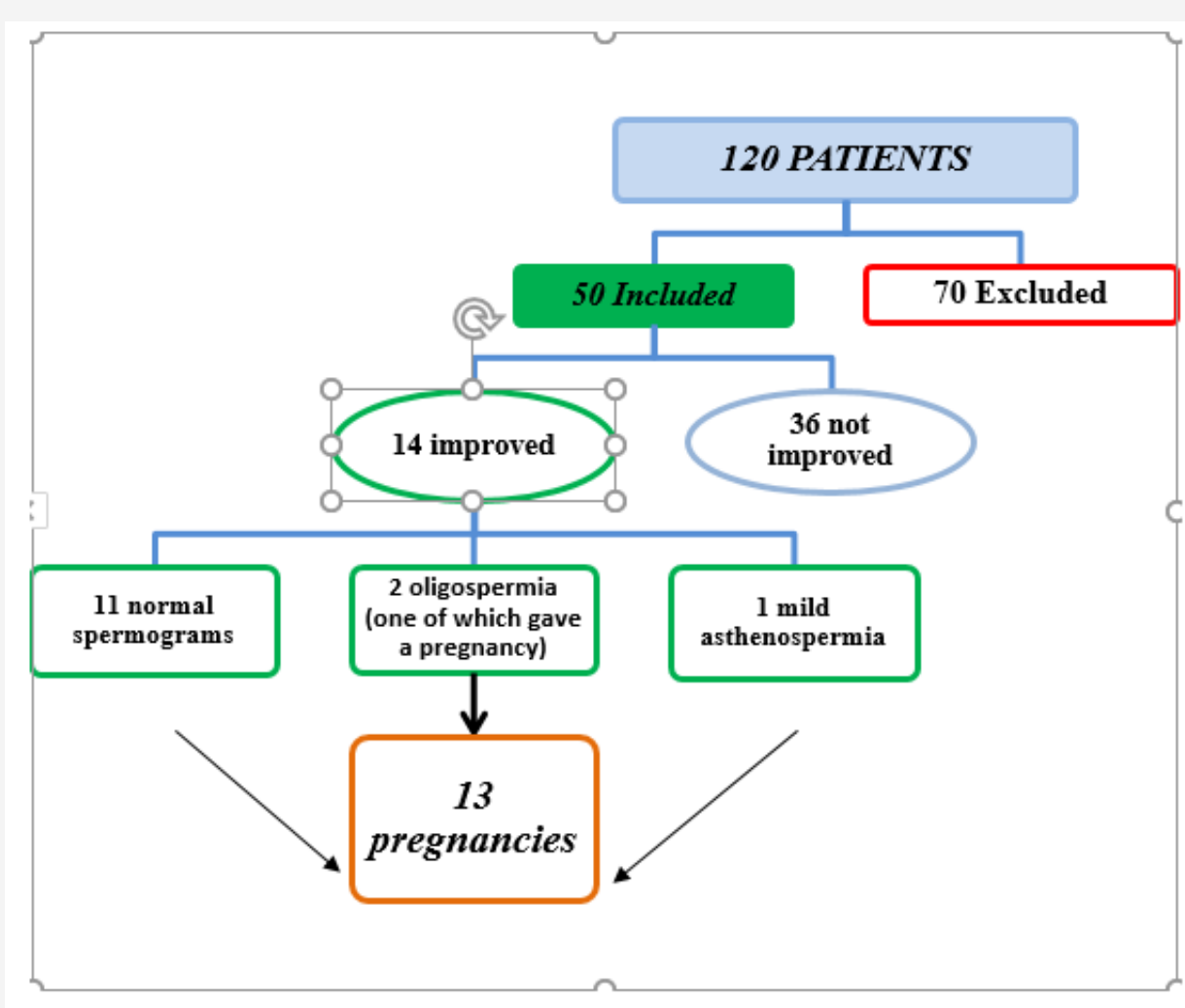

Figure 2: Mode of delivery of both groups. 


\section{Discussion}

Varicocele is the leading reversible cause of infertility which is defined as the inability of a couple to get a pregnancy after one year of intercourse without male contraception. It is observed in $35 \%$ to $40 \%$ of all men with primary infertility and up to $80 \%$ of those with secondary infertility, defined by the presence of an abnormal varicose dilatation of the veins of the anterior plexiform plexus testis. Clinical varicoceles develop unilaterally on the left in $85 \%$ to $90 \%$ of cases. Anatomy explains this almost exclusive predominance. The benefit of treatment of varicocele in the management of male infertility is still controversial, despite the many published works dealing with this subject. In our study, the most frequent abnormalities observed in order of frequency were respectively oligo-astheno-teratozoospermia in 29 cases (59\%) oligo-astheno-ospermia in 14 cases (27\%), asthenospermia in 7 cases (14\%), something that flows in the same direction compared to the results found in the literature; according to F. Comhaire and A. Mahmoud sperm analysis is most often found an oligoastheno-terazoospermia that is accompanied by a normal volume of ejaculate, or even hyperspermia [4].

In contrast, in the more recent study by Mori et al. Among 360 adolescents, a decrease in mobility and sperm concentration is associated with varicocele, regardless of the grade of the sperm. However, the decrease in mobility is greater when the grade of varicocele is higher [5]. Yamamoto and al. had suggested in a prospective randomized study in 1996 that treatment of subclinical varicoceles did not provide fertility benefit [6]. But this has been repeated and confirmed in more recent recommendations $[7,8]$; that palpable varicoceles represent the only entity requiring a therapeutic act. This is confirmed by the meta-analysis of Agarwal in 2007, which points to a net increase in sperm parameters [2]. Which goes in the same direction with our results.

The Cochrane Collaboration reports that there is no benefit in terms of fecundity after treatment of varicoceles [9]. Nevertheless, Ficarra et al. [10] carried out a new meta-analysis based on the same data from the latter and found a significant increase in the rate of pregnancies in couples treated for varicocele $(36.4 \%)$ compared to those not treated (20\%). When to Marmar and al. in 2007 , they reported a pregnancy rate of $33 \%$ in patients treated for varicocele versus $15.5 \%$ in untreated patients [11]. Also, Cayan and al found spontaneous postoperative pregnancy was reported in $39.07 \%$ [12]. The percentage of pregnancies obtained after varicocele surgery varies, depending on the series, from 20 to $60 \%$, with an average value of $32.4 \%$ according to Schelesinger et al. [13], thus, for Fazelin et al. [14], 43\% of couples had a pregnancy in the first year after treatment and 69\% in 2 years. Richardson et al. [15] evaluated 2291 pairs in 24 studies and reported an average natural birth rate of $39.5 \%$, in addition to recovery of sperm parameters after repair of varicoceles. Abdel-Meguid et al. [16] examined 145 male patients, with a minimum of one year of infertility, who were followed without repair of varicocele $(n=72)$ or with varicocele repair $(n=73)$. While the natural pregnancy rate during follow-up was $13.9 \%$ in the group without varicocele repair, it was $32.9 \%$ in the varicocele repair group.

In 2009, Cayan et al. [17] analyzed the pregnancy rate after varicocele repair to define the best technique based on the results of 36 studies. They concluded that the microsurgical varicocelectomy technique has higher spontaneous pregnancy rates and lower postoperative recurrence than conventional varicocelectomy and radiologic embolization techniques in infertile men. Similarly, Diegidio et al. [18] reviewed more than 5,000 data from 33 studies conducted in 2011 with patients. The overall pregnancy rate was established at $38.37 \%$ (954/2486) by simple addition and division. The pregnancy rate was highest for the microsurgical subenguinal technique (44.75\%) and the microsurgical inguinal technique (41.78\%). Other techniques seem to have a lower pregnancy rate than the microsurgical technique. For example, the pregnancy rate with the Palomo technique was $34.21 \%, 31.93 \%$ for radiological embolization, $30.06 \%$ for the conventional inguinal technique and $27.53 \%$ for the laparoscopic technique.

While most authors are unanimous that varicocele treatment improves fertility and sperm quality, Evers and Collins [19], whose meta-analysis does not suggest fertility improvement in a couple even after treatment of varicocele, but the peculiarity of this meta-analysis is the fact of having included patients with normal spermogram, but also those with subclinical varicocele which our sense does not really allow us to appreciate the effectiveness of a treatment. Compared to the literature in our series after surgery this pregnancy rate is $26 \%$, although our numbers are low compared to the figures advanced by the studies, but it must be emphasized that this still represents a significant improvement.

\section{Conclusion}

In the case of infertility associated with a clinically palpable varicocele, the surgical treatment of varicocele offers an excellent opportunity to improve the quality of sperm, in order to have spontaneous pregnancy in $26 \%$ of cases in our study. However, only a randomized controlled prospective study will confirm or refute these findings.

\section{Acknowledgement}

None.

\section{Conflict of Interest}

No conflict of Interest.

\section{References}

1. Baazeem A, Belzile E, Ciampi A, Dohle G, Jarvi K, et al. (2011) Varicocele and male factor infertility treatment: a new meta-analysis and review of the role of varicocele repair. Eur Urol 60(4): 796-808.

2. Agarwal A, deepinder F, cocuzza M, Agarwal R, Short RA, et al. (2007) Efficacy of varicocelectomy in improving semen parameters: new metaanalytic approach. Urology 70(3): 532-538.

3. EAU guidelines 2018

4. Comhaire F, Mahmoud A (2006) In Andrology for the Clinician, Berlin Heidelberg: Springer, Implications of multifactorial aetiology in the diagnosis and management of male infertility pp: 33-35. 
5. Mori MM, Bertolla RP, Fraietta R, Ortiz V, Cedenho AP (2008) Does varicocele grade determine extent of alteration to spermatogenesis in adolescents? Fertility and sterility 90(5): 1769-1773.

6. Yamamoto M, Hibi H, Hirata y, Miyake K, Ishigaki T (1996) Effect of varicocelectomy on sperm parametersand pregnancy rate in patients with subclinical varicocele: a randomized prospective controlled study. J Urol 155: 1636-1638

7. Jarow JP, Sharlipi D, Belker AM (2002) Male infertility best practice policy committee of the American urological association Inc J Urol 167: 2138-2344.

8. Dohle GR, Colpi GM, Hargreave TB (2005) Eau guidelines on male infertility. Eur Urol 48: 703-711.

9. Evers JL, Collins JA, Vandekerckhove P (2001) Surgery or embolisation for varicocele in, sub fertile men. Cochrane database syst Rev 3 : CD000479

10. Ficarra V, Cerruto MA, ligouri G, Mazzano G, Minucci S, et al. (2006) Treatment of varicocele in sub fertile men: the Cochrane review a contrary opinion. Eur Urol 49: 258-263.

11. Marmar JL, agarwal A, prabakaran S, agarwal R, short RA, et al. (2007) Reassessing the value of varicocelectomy as treatment for male subfertility with a new meta-analysis. fertil Steril 88: 639-648.

12. Cayan S, shavakhabov S, kadioğlu A (2009) Treatment of palpable varicocele in infertile men: a meta-analysis to define the best technique. J Androl 30(1): 33-40.
13. Schlesinger MH, Wilets IF, Nagler HM (1994) Treatment outcome after varicocelectomy: acritical analysis. Urol Clin North Am 21: 517-553.

14. Fazelin Martin S, Morrison G, Goldstein M (1994) What is the pregnancy rate in vasovasostomy and varicocelectomy patients who are «lost to follow-up»? J Urol 151: 303A.

15. I Richardson, AB Grotas, HM Nagler (2008) Résultats du treatment de la varicocélectomie: une analyse critique mise à jour Urol Clin North Am 35: 191-209.

16. TA Abdel Meguid, A Al Sayyad, A Tayib, HM Farsi Est (2011) ce que la réparation de varicocèle améliore l'infertilité masculine? Une perspective fondée sur des données probantes provenant d'un essai contrôlé randomisé. EUR Urol 59: 455-461.

17. Cayan S, Shavakhabov S, Kadioğlu A (2009) Treatment of Palpable Varicocele in Infertile Men: A Meta-analysis to Define the Best Technique. Journal of andrology 30(1): 33-40.

18. Diegidio P, Jhaveri JK, S Ghannam, R Pinkhasov, Shabsigh R, et al. (2011) Examen des techniques actuelles de varicocélectomie et de leurs résultats. Bju Int 108: 1157-1172.

19. Kroese AC, de Lange NM, Collins J, Evers JL (2004) Surgery or embolization for varicocele in sub fertile men. Cochrane Database Syst Rev 10: CD000479. 